\title{
Tracheostomy - The forgotten difficult airway?
}

DOI:

10.1016/j.tacc.2016.10.004

\section{Document Version}

Accepted author manuscript

Link to publication record in Manchester Research Explorer

\section{Citation for published version (APA):}

McGrath, B. A., \& Haley, D. (2017). Tracheostomy - The forgotten difficult airway? Trends in Anaesthesia and Critical Care, 13, 22-24. https://doi.org/10.1016/j.tacc.2016.10.004

\section{Published in:}

Trends in Anaesthesia and Critical Care

\section{Citing this paper}

Please note that where the full-text provided on Manchester Research Explorer is the Author Accepted Manuscript or Proof version this may differ from the final Published version. If citing, it is advised that you check and use the publisher's definitive version.

\section{General rights}

Copyright and moral rights for the publications made accessible in the Research Explorer are retained by the authors and/or other copyright owners and it is a condition of accessing publications that users recognise and abide by the legal requirements associated with these rights.

\section{Takedown policy}

If you believe that this document breaches copyright please refer to the University of Manchester's Takedown Procedures [http://man.ac.uk/04Y6Bo] or contact uml.scholarlycommunications@manchester.ac.uk providing relevant details, so we can investigate your claim.

\section{OPEN ACCESS}


Title page

Tracheostomy - the forgotten difficult airway?

\section{Authors}

\section{Brendan A McGrath ${ }^{\mathrm{a}, 1,2,3,{ }^{*}}$ \& Daniel Haley ${ }^{\mathrm{a}, 4}$}

a. University Hospital of South Manchester, Southmoor Road, Wythenshawe, Manchester, UK. M23 9LT.

1. Consultant in Anaesthesia \& Intensive Care Medicine

2. Honorary Senior Lecturer, University of Manchester

3. European Lead, Global Tracheostomy Collaborative

4. Speciality Trainee in Intensive Care Medicine, Health Education North West

*Corresponding author, Dr BA McGrath

Acute Intensive Care Unit,

University Hospital of South Manchester, Southmoor Road, Wythenshawe, Manchester, UK. M23 9LT.

Brendan.mcgrath@manchester.ac.uk 


\section{Abstract}

The demographics and clinical characteristics of patients with tracheostomies and laryngectomies are evolving. Many will have encounters with medical, nursing and allied health staff from a variety of backgrounds and leadership can be expected from those with an interest or expertise in airway management. Recurrent themes have been identified that lead to harm for this vulnerable group, whilst at the same time, others have demonstrated that educational programmes and infrastructure adaptations can improve care. We highlight the steps that all airway specialists can take to influence the quality and safety of care that we provide in our institutions. 


\section{Introduction}

Tracheostomies are historically seen as the domain of head \& neck surgeons, but anaesthetists and non-surgeons are increasingly called upon to manage routine and emergency tracheostomy care and must be equipped to do so. This article highlights the problems that commonly occur with tracheostomies and the steps that all airway specialists can take to influence the quality and safety of care that we provide in our institutions to this vulnerable group of patients.

Tracheostomy is one of the earliest described surgical procedures, with descriptions found on ancient Egyptian clay tablets dating back to 3600 BC. Instruction in the surgical technique can be found in Ebers's Papyrus, dating back to about 1550 BC, but also in Hindi holy scriptures, the Rig Veda, dating back to $2000 \mathrm{BC}$.[1] The first 'modern' surgical tracheostomy is commonly credited to Antonio Brasavola in 1546. These procedures were usually undertaken to provide emergency surgical airways and whilst this indication remains, the advent of modern critical care and the utility of bedside percutaneous tracheostomy has introduced a new cohort of patients with 'medical' problems, with the majority of procedures now performed percutaneously in Intensive Care Units (ICUs).[2,3]

Patients managed in our hospitals with temporary or permanent tracheostomies on wards or in critical care units are exposed to a wide range of healthcare professionals and specialities, with the anaesthetist and critical care specialists often pivotal in their inpatient journey. Despite this, it is surprisingly difficult to find national data on the number of patients managed with tracheostomy. What detailed data there are suggests that $7-19 \%$ of all patients admitted to an Intensive Care Unit (ICU) will be managed with a tracheostomy, and that up to $90 \%$ of these ICU tracheostomies are currently performed by percutaneous routes.[4,5] This figure varies with the admission diagnosis, individual units, and to some extent, the country.[2,6-8] 


\section{What's the problem with tracheostomies?}

Problems with tracheostomy care have been highlighted following recent reports from around the world identifying measurable harm in up to $30 \%$ of all acute hospital admissions involving temporary or permanent tracheostomy.[3,913] The very need for tracheostomy can be considered an indicator of increased morbidity and mortality. Mortality rates during the index hospital admission have been demonstrated to range from $17-20 \%$, rising to $40 \%$ in groups with significant comorbidities.[11,12] Whilst much of this burden is due to the underlying illness, harm may occur that can be directly associated with the management of the airway device. $[9,10]$ Systematic analysis of reported adverse incidents has revealed common underlying themes which include a lack of staff training, lack of basic bedside equipment, and inadequate environments and support mechanisms, compounded by poorly thought out care pathways and responses to incidents. $[9,14]$ These findings were reinforced by the 4 th National Audit Project of the UK Royal College of Anaesthetists (NAP4) which reported similar problems in a subset of major tracheostomy incidents that occurred in the UK's critical care units in 2011.[13]

The UK National Confidential Enquiry into Patient Outcome and Death (NCEPOD) conducted a UK-wide study into tracheostomy care in 2014, the lessons of which are applicable to any western healthcare system.[3] The report analysed airway management during surgical tracheostomy and found that of the patients undergoing tracheostomy in the operating theatre, $14.4 \%$ had stridor and $29.1 \%$ were recognized as being potentially difficult to re-intubate, with concerns about oxygenation prior to intubation in $13.4 \%$. Of the patients who were intubated, nearly $20 \%$ required the use of additional difficult airway equipment. There was at least one failed attempt at intubation in $6 \%$ of patients and in $3 \%$ of cases the anaesthetist was unable to intubate or ventilate at some point during the procedure. As in NAP4, obesity was a significant factor, with complications disproportionately increased in the $30 \%$ of patients who were classified as obese in the NCEPOD study. Whilst patients requiring elective or emergency tracheostomy might be expected to have a difficult airway, these data help to 
quantify this risk, and should serve as a timely reminder to anaesthetists who may be called upon infrequently to manage these situations.[14]

Anaesthetists and critical care specialists will usually have first hand experience of dealing with routine and emergency care of 'neck breathing' patients. They are also the professional group most likely to be involved acutely when care does not go well, as airway specialists, resuscitation experts and intensivists.

\section{Emergency management of tracheostomy problems}

Airway management in the critically ill can be difficult, even in the context of an anatomically 'normal' airway. These difficulties can be compounded when a tracheostomy is in situ, and the native airway is frequently altered by oedema, trauma or prolonged trans-laryngeal intubation.[15] Patients may be hypoxic, obtunded or combative, and commonly will have intra-abdominal pathology, functional gastric stasis or not be fasted. The majority will have unstable physiology which is compounded by administration of sedative anaesthetic agents. Pre-existing hypoxia, ventilation-perfusion mismatch, absolute or relative hypovolaemia and myocardial impairment all contribute to a lack of cardiorespiratory reserve that increases the risk of deterioration, cardiac arrest and death.[16,17] Rapid desaturation from a hypoxic baseline creates time pressure and demands rapid action, turning a technically uncomplicated procedure into a stressful event for patients and staff.[18] Unfamiliarity with tracheostomies, laryngectomies and related equipment can compound these problems. A lack of knowledge amongst junior and senior medical staff has been demonstrated, again compounded by poor knowledge from airway assistants, a lack of skilled assistance and inadequate equipment when managing the airways and tracheostomies of critically ill patients. These factors may impact on the delivery of prompt, safe and skilled airway management, especially when difficulty occurs and non-standard plans are required.[19-21]

In response to our understanding of the common problems with tracheostomy care, the UK National Tracheostomy Safety Project (NTSP, 
www.tracheostomy.org.uk) was formed in 2009. The NTSP formed a working party with multidisciplinary representation from key stakeholders in tracheostomy care, publishing the first multidisciplinary guidelines for the emergency management of tracheostomy and laryngectomy problems in 2012.[22]. These algorithms are now taught worldwide and guide the responder to provide oxygenation and to troubleshoot and manage the commonest tracheostomy problems in a sequential manner. The algorithms are supported by an educational package, videos demonstrating key steps and accessible free resources suitable for all staff involved in tracheostomy care. Introducing the educational resources of the NTSP, coupled with reorganisations and reductions in the number of locations in which tracheostomy patients were managed, was associated with a significant reduction in harm in four large UK teaching hospitals.[23]

\section{Prevention of tracheostomy problems though quality improvement}

Whilst the focus of the airway specialist is often the management of the potentially difficult airway during tracheostomy insertion, the vast majority of adverse incidents occur more than one week after initial tracheostomy. Fortunately, many of these events are due to factors which are amenable to prospective, system-wide, quality improvement strategies.[24] Examples of such strategies have been reported from a variety of institutions, and include multidisciplinary team working, multidisciplinary ward rounds and bedside checklists and bundles.[25-32]

In 2006, Frank et al[25] reported on the multidisciplinary team management approach to the treatment of patients with severe neurogenic dysphagia, implementing a swallowing therapy and decannulation programme and consequently demonstrating significant reductions in time to decannulation. Hunt and McGowan[26] described similar improvements in neurology patients as a result of a specialist tracheostomy team consisting of a physiotherapist, speech pathologist, nurse and anaesthetist in 2005. Others have shown that complications can be reduced by implementing dedicated multidisciplinary 
ward-based teams, led by nurses[27] and by intensivists.[28] Tobin and Santamaria reported a meaningful trend to reduced decannulation times and also a significant reduction in hospital length of stay and hospital stay after ICU discharge.[28] They found improved decannulation rates across the period of the study, with the effect of the team intervention improving over time. Surgeon-led multidisciplinary teams have also been shown to impact on the quality and safety of care, exemplified by Hettige and Arora.[30] They described the implementation of a ward-based tracheostomy care bundle in a central London teaching hospital, associated with a reduction in serious tracheostomy-related critical events. Their initial work led to an expanded tracheostomy team, including specialist nursing staff, speech and language pathologists, respiratory physiotherapists, dieticians, respiratory physicians, surgeons, anaesthetists and intensivists who provided regular review, championed bedside safety checklists and delivered educational programs to relevant staff. These interventions reduced length of ICU and in-patient stay, whilst reducing overall time to tracheostomy tube decannulation.[24,29]

These initiatives have reported varied improvements in decannulation times and also a significant reduction in hospital and ICU length of stay, improved decannulation rates and times, and reduction in patient safety incidents. In 2009, Cameron's group in Australia introduced a tracheostomy review and management service (TRAMS) to their tertiary unit, also demonstrating improved outcomes, with patients leaving acute care sooner and the tracheostomy tube being removed earlier, with associated significant cost savings.[33] What Cameron was able to repeatedly demonstrate was these initiatives were also associated with improvements in surrogates for better quality care, with patients speaking and swallowing sooner.

By working more closely with multidisciplinary colleagues and in a more coordinated manner, Pandian and colleagues were able to positively influence the timing and safety of percutaneous tracheostomy for critically ill patients.[31] She described associated decreases in post-procedure complications such as 
bleeding and physiological disturbances, with reductions in lengths of stay for the largest subgroups.

These examples of improvements in care have tended to be reported in single institutions and this led to the forming of the Global Tracheostomy Collaborative (GTC, www.globaltrach.org) in 2012. The GTC brings together multidisciplinary representation, with patients, their families and carers to guide providers in delivering the best care possible based on the available evidence. The GTC is a not-for-profit company registered in the USA and has recruited over 60 worldwide sites to date. Participating institutions are encouraged to adopt new and innovative ways of working from exemplar centres, share resources and appoint medical, non-medical and patient champions to oversee changes in the care provided. Patient level data is entered into a secure database to allow realtime analysis of trends in surrogates for the quality and safety of care and to provide feedback at institutional level to drive change. Early reports of improvements in a detailed evaluation of implementation of the GTC into four diverse UK NHS sites was extremely encouraging [34] and the first detailed publications from the GTC are awaited with interest. 


\section{Conclusion}

What it clear is that tracheostomies should no longer be the forgotten airway, with increasing understanding of associated problems for patients and their families as well as the healthcare professionals who care for them. Anaesthetists and critical care specialists are well versed in managing complex teams, systems and situations, and can play a key role in leading, coordinating and contributing to improvements in multidisciplinary tracheostomy care. Our role is not just in responding to airway emergencies, but in ensuring that these vulnerable patients do not come to harm in our institutions, wherever they are managed. If it could happen in your hospital, it should be our responsibility to do something about it.

\section{Acknowledgement}

The authors are grateful to the members and committees of the Global Tracheostomy Collaborative (GTC) for their assistance in preparing this manuscript. The GTC is hosting a number of international meetings over the next 12 months to explain more about the Collaborative. The next meeting is part of the European Society of Intensive Care Medicine Annual Congress in Milan, Monday 3rd October 2016. See www.globaltrach.org for further details of this and future meetings. 


\section{References}

[1] J. Olszewski, J. Miłoński, History of tracheotomy Otolaryngol Pol. 2007;61:349-352.

[2] B.A. McGrath, R. Ramsaran, M.O. Columb, Estimating the number of tracheostomies performed in critical care in England, Br J Anaesth. 2012;109:662P.

[3] K.A. Wilkinson, I.C. Martin, H. Freeth, K. Kelly, M. Mason, NCEPOD: On the right Trach? (2014). www.ncepod.org.uk/2014tc.htm (accessed August 20, 2016).

[4] T. Veenith, S. Ganeshamoorthy, T. Standley, J. Carter, P. Young, Intensive care unit tracheostomy: a snapshot of UK practice. Int Arch Med. 2008;1:21.

[5] D. Young, D.A. Harrison, B.H. Cuthbertson, K. Rowan, F.T. TracMan Collaborators, Effect of Early vs Late Tracheostomy Placement on Survival in Patients Receiving Mechanical Ventilation, JAMA 2013;309:2121.

[6] A.B. Nathens, F.P. Rivara, C.D. Mack, G.D. Rubenfeld, J. Wang, G.J. Jurkovich, et al., Variations in rates of tracheostomy in the critically ill trauma patient, Critical Care Medicine 2006;34:2919-2924.

[7] L. Fischler, S. Erhart, G.R. Kleger, A. Frutiger, Prevalence of tracheostomy in ICU patients. A nation-wide survey in Switzerland, Intensive Care Med. 2000;26:1428-1433.

[8] F. Blot, C. Melot, Commission d'Epidémiologie et de Recherche Clinique, Indications, timing, and techniques of tracheostomy in 152 French ICUs, Chest 2005;127:1347-1352.

[9] A.N. Thomas, B.A. McGrath. Patient safety incidents associated with airway devices in critical care: a review of reports to the UK National Patient Safety Agency, Anaesthesia 2009;64(4):358-365.

[10] B.A. McGrath, A.N. Thomas, Patient safety incidents associated with tracheostomies occurring in hospital wards: a review of reports to the UK National Patient Safety Agency, Postgrad Med J. 2010;86:522-525.

[11] S.L. Halum, J.Y. Ting, E.K. Plowman, P.C. Belafsky, C.F. Harbarger, G.N. Postma, et al., A multi-institutional analysis of tracheotomy complications, Laryngoscope. 2012;122:38-45.

McGrath \& Hayley. Tracheostomy - the forgotten difficult airway? 
[12] R.K. Shah, L. Lander, J.G. Berry, B. Nussenbaum, A. Merati, D.W. Roberson, Tracheotomy outcomes and complications: a national perspective, Laryngoscope. 2012;122:25-29.

[13] T.M. Cook, N. Woodall, C. Frerk, on behalf of the Fourth National Audit Project, Major complications of airway management in the UK: results of the Fourth National Audit Project of the Royal College of Anaesthetists and the Difficult Airway Society. Part 1: Anaesthesia, Br J Anaesth. 2011;106:617-631.

[14] B.A. McGrath, K. Wilkinson, The NCEPOD study: on the right trach? lessons for the anaesthetist, BrJ Anaesth. 2015;115(2):155-8.

[15] J. Astin, E.C. King, T. Bradley, E. Bellchambers, T.M. Cook, Survey of airway management strategies and experience of non-consultant doctors in intensive care units in the UK, BrJ Anaesth. 2012;109:821-825.

[16] T.C. Mort, B.H. Waberski, J. Clive, Extending the preoxygenation period from 4 to 8 mins in critically ill patients undergoing emergency intubation, Critical Care Medicine. 2009;37:68-71.

[17] A.B. Leibowitz, Persistent preoxygenation efforts before tracheal intubation in the intensive care unit are of no use: who would have guessed? Critical Care Medicine. 2009;37:335-336.

[18] S. Jaber, J. Amraoui, J.-Y. Lefrant, C. Arich, R. Cohendy, L. Landreau, et al., Clinical practice and risk factors for immediate complications of endotracheal intubation in the intensive care unit: A prospective, multiple-center study, Critical Care Medicine. 2006;34:2355-2361.

[19] T.C. Mort, Emergency Tracheal Intubation: Complications Associated with Repeated Laryngoscopic Attempts, Anesth. Analg. 2004;99(2):607-13

[20] D.E. Schwartz, M.A. Matthay, N.H. Cohen, Death and other complications of emergency airway management in critically ill adults. A prospective investigation of 297 tracheal intubations, Anesthesiology. 1995;82:367-376. [21] L.D. Martin, J.M. Mhyre, A.M. Shanks, K.K. Tremper, S. Kheterpal, 3,423 emergency tracheal intubations at a university hospital: airway outcomes and complications, Anesthesiology. 2011;114:42-48.

[22] B.A. McGrath, L. Bates, D. Atkinson, J.A. Moore, Multidisciplinary guidelines for the management of tracheostomy and laryngectomy airway emergencies, Anaesthesia. 2012;67:1025-1041.

McGrath \& Hayley. Tracheostomy - the forgotten difficult airway? 
[23] B.A. McGrath, N. Calder, S. Laha, A. Perks, I. Chaudry, L. Bates, et al., Reduction in harm from tracheostomy-related patient safety incidents following introduction of the National Tracheostomy Safety Project: Our experience from two hundred and eighty seven incidents, Clin Otolaryngol. 2013;38:541-545.

[24] R. Hettige, A. Arora, D.W. Roberson, A.A. Narula, Recent developments to improve the standards of tracheostomy care, British Journal of Intensive Care. 2013;Summer:89-92.

[25] U. Frank, M. Mäder, H. Sticher, Dysphagic patients with tracheotomies: a multidisciplinary approach to treatment and decannulation management, Dysphagia. 2007;22:20-29.

[26] K. Hunt, S. McGowan, Tracheostomy management in the neurosciences: a systematic, multidisciplinary approach. British Journal of Neuroscience Nursing. 2005;1:122-125.

[27] M.G.A. Norwood, P. Spiers, J. Bailiss, R.D. Sayers, Evaluation of the role of a specialist tracheostomy service. From critical care to outreach and beyond, Postgrad Med J. 2004;80:478-480.

[28] A.E. Tobin, J.D. Santamaria, An intensivist-led tracheostomy review team is associated with shorter decannulation time and length of stay: a prospective cohort study, Crit Care. 2008;12:R48.

[29] R. Cetto, A. Arora, R. Hettige, M. Nel, L. Benjamin, C.M.H. Gomez, et al., Improving tracheostomy care: a prospective study of the multidisciplinary approach, Clin Otolaryngol. 2011;36:482-488.

[30] R. Hettige, A. Arora, S. Ifeacho, A. Narula, Improving tracheostomy management through design, implementation and prospective audit of a care bundle: how we do it, Clin Otolaryngol. 2008;33:488-491.

[31] V. Pandian, C.R. Miller, M.A. Mirski, A.J. Schiavi, A.H. Morad, R.S. Vaswani, et al., Multidisciplinary Team Approach in the Management of Tracheostomy Patients, Otolaryngology - Head and Neck Surgery. 2012;147:684-691.

[32] L. Speed, K.E. Harding, Tracheostomy teams reduce total tracheostomy time and increase speaking valve use: A systematic review and meta-analysis, Journal of Critical Care. 2013;28(2):216.

[33] T.S. Cameron, A. McKinstry, S.K. Burt, M.E. Howard, R. Bellomo, D.J. Brown, et al., Outcomes of patients with spinal cord injury before and after McGrath \& Hayley. Tracheostomy - the forgotten difficult airway? 
introduction of an interdisciplinary tracheostomy team, Crit Care Resusc. 2009;11:14-19.

[34] Lynch et al. Improving multidisciplinary tracheostomy care:

implementing the Global Tracheostomy Collaborative quality improvement project. 2015. Available at:

http://www.health.org.uk/sites/health/files/UHSM\%20final\%20report.pdf (Accessed 20 th August 2016) 